\title{
Social interventions in mental health: a call to action
}

\author{
Sonia Johnson ${ }^{1}[$
}

Received: 9 January 2017 / Accepted: 29 January 2017 / Published online: 6 March 2017

(C) Springer-Verlag Berlin Heidelberg 2017

With this editorial, I am pleased to introduce a series of reviews on the state of the art in social interventions in mental health. That mental health is intertwined with the social is now accepted by all but the most diehard reductionists. Recent integrated aetiological models bring social factors, such as discrimination and deprivation into the neuroscientific mainstream [1], as explored in a previous Social Psychiatry and Psychiatric Epidemiology series [2]. Meanwhile, advances in data science and epidemiological methods allow deeper understanding of long-established relationships between mental health and social variables [3]. The relationship between social adversity and mental health problems appears bidirectional [4]: social adversity increases risk of poor mental health, and having a mental health condition increases risk of poor social circumstances and limited social connections. An important task for future research is to clarify these complex relationships and the pathways linking social determinants and mental health outcomes, with a view especially to identifying potential targets for intervention [5].

Even though the relationship between the social and mental health is well-established, the social remains the poor relative in the biopsychosocial triad when it comes to evidence-based interventions, such as in guideline recommendations. For example, NICE guidance for major adult mental health conditions has very brief lists of suggested social interventions alongside much more extensive lists of psychological and pharmacological interventions $[6,7]$.

Sonia Johnson

s.johnson@ucl.ac.uk

1 Division of Psychiatry, University College London, London, UK
Potential reasons for this evidence gap are readily identified. First, the most obvious responses to social determinants of mental ill health, such as poverty and inequality, are political. An attempt to intervene with individuals to mitigate the consequences of social adversity may be seen as a reductionist diversion of attention from the need for wider societal change [8]. Second, clinical professionals and researchers may feel in danger of paternalism and overstepping role boundaries if they contemplate intervening in areas of private life such as friendships, or they may feel overwhelmed and powerless in the face of the severe social difficulties that many service users face. Third, the range of potential targets for social interventions is dauntingly wide and extends far beyond mental health services, encompassing individual, family, community and societal levels. Fourth, although there are few well-specified and evidencebased interventions that meet criteria for guideline inclusion, forms of help focused on the social have long been offered in many settings. Day centres and sheltered housing are among the environments in which workers offer service users help with social problems and with enhancing their social activities and connections. One might argue that these workers, often people with considerable interpersonal skills and life experience, know how to tailor interventions to clients' individual circumstances, making development of more structured interventions unnecessary and a possible threat to individualisation. Finally, the dominant clinical professions in mental health care research are psychiatry and psychology, with a less developed research workforce in social care.

And yet there are compelling reasons to promote more extensive development and testing of interventions aimed at preventing and/or improving outcomes of mental health problems via social pathways. First, as a group of influential advocates of a social paradigm in 
mental health research have recently argued [9], several decades of energetic research on neuroscientific and psychological approaches in mental health have resulted in relatively little evidence of improved outcomes. Thus there is a case for trying new directions: the promise of the social lies in our knowledge that it is a powerful influence on both onset and outcomes of mental health problems. Second, when consulted regarding priorities for mental health care and mental health research, service users advocate more focus on goals that include reducing stigma and social exclusion, understanding and alleviating the impact on mental health of social adversities, and promoting good relationships and support within communities, [10, 11]. Third, there are substantial benefits in establishing an evidence base for social interventions rather than relying on intuitions about what may work. Employment exemplifies this: long-held assumptions that people with mental illnesses benefit from work preparation such as through sheltered workshops have been overturned through research on supported employment [12]. Untested social interventions proliferate: an interesting and increasingly widespread model in the UK is social prescribing, but as yet we do not have substantial evidence regarding its outcomes or effective variants [13]. Fourth, without robust evidence, including on health economics, it is difficult to make a strong case for funding for social interventions, or for prioritising them in guidelines. Finally, there is a strong consensus that prevention in mental health should be prioritised, even though investment in this lags greatly behind rhetoric in most countries. Many potential targets for preventive intervention are social, but with a handful of exceptions, evidence to guide priorities is still very limited $[14,15]$.

While the evidence on social interventions is not yet sufficiently substantial or widely recognised to achieve prominence in clinical guidance, we do have some starting points for their development, evaluation and implementation. The four reviews introduced by this editorial focus on social interventions with varying targets, at levels including individual, community and society.

Loneliness has recently become the focus of increasing interest, especially in research on older people's health, with evidence of significant adverse effects on both physical and mental health [16]. Mann et al. [17] describe potential approaches to loneliness among people who have mental health problems or are at risk of developing them. These range from individual interventions, targeting cognitive and emotional aspects of loneliness or supporting people in forming new connections, to ambitious programmes aimed at augmenting community assets. Evaluation of impacts on mental health outcomes has been limited, but there is some evidence that it is possible to reduce loneliness through various strategies, a potential starting point for investigation of whether mental health problems may be averted or alleviated by reducing loneliness.

Webber and Fendt-Newlin [18] focus more narrowly in their review of social participation on interventions to increase social network size in people with mental health problems. A range of strategies is identified, including individual-level support in increased engagement with others, individual and group social skills training, and groups involving participating in activities with others. Again the conclusion is that it appears possible to increase social connections, but the evidence remains weak on the best approaches and the impact on mental health outcomes. The authors identify a need to investigate how mental health services can best engage with local communities to enhance community assets and promote service user participation.

With the review by Henderson et al. [19] on interventions to reduce stigma, the perspective broadens from areas in which interventions have mainly been directed at individuals with mental health problems, to one of few areas in which large-scale attempts have been made to achieve change in wider communities and societies. Some inspiring successes achieved through a variety of strategies are balanced against the short timescale of many interventions and the need to establish how change can be sustained.

Perhaps, the most potentially radical and exciting of the papers is that of Wahlbeck and colleagues [20]: they take a very broad perspective in examining whether any interventions are effective in mitigating the ill-effects of structural determinants of mental health, such as poverty and inequality. A framework of potential interventions is outlined to address these determinants and the upstream factors by which they may result in poor mental health. These include interventions at country, neighbourhood, family and individual level, with potential foci, including debt, employment conditions, parenting, housing, neighbourhood levels of violence and social cohesion, and education. In many areas the idea of developing and testing specific interventions to improve mental health remains mainly aspirational. However, notable exceptions include targeted parenting interventions to reduce inequalities in parents' ability to meet their children's needs, early health visiting programmes and schools' mental health programmes, all of which have some supporting evidence as means of reducing the impact of structural inequalities on mental health. Beyond this, observational evidence suggests many potential targets for efforts to redress the effects of structural factors, but little evidence as to what works best.

Thus, in these four papers, much of what is currently known regarding evidence for social interventions in mental health is mapped out. Important areas not covered are employment, where the evidence, more substantial than for other social interventions, indicates a large effect for the Individual Placement and Support model [21], and housing 
$[22,23]$. Taken together, the papers surely constitute a call to action: established knowledge regarding the impact of the social on mental health needs to be matched by a range of well-evidenced interventions for whose effectiveness and cost-effectiveness we may confidently argue. Beyond this, those involved and interested in mental health may also consider whether they should contribute to addressing the social determinants of mental health by other means, for example through political advocacy and activism. Targeted interventions in areas such as parenting and education show some success in addressing the adverse effects on mental health of social deprivation and inequality, but it is unlikely that they can do so as effectively as social, political and economic change that directly reduces these powerful negative influences. Inequality is growing worldwide and its effects on health and well-being are increasingly clear [24, 25]: thus alongside development of social interventions as described in this series of articles, there is a compelling case for researchers and others involved in mental health to be public mental health advocates, making the case for investment in national and local policies that directly target the social roots of mental ill health [26].

\section{Compliance with ethical standards}

She is in part supported by the National Institute for Health Research (NIHR) Collaboration for Leadership in Applied Health Research and Care (CLAHRC) North Thames at Bart's Health NHS Trust. The views expressed are those of the author(s) and not necessarily those of the NHS, the NIHR or the Department of Health.

Conflict of interest The author has no conflict of interest.

\section{References}

1. Howes OD, Murray RM (2014) Schizophrenia: an integrated sociodevelopmental-cognitive model. Lancet 383(9929):1677-1687

2. Reininghaus U, Morgan C (2014) Integrated models in psychiatry: the state of the art. Soc Psychiatry Psychiatr Epidemiol 49:1-2

3. Allen J, Balfour R, Bell R, Marmot M (2014) Social determinants of mental health. Int Rev Psychiatry 26(4):392-407

4. Almquist YB, Landstedt E, Hammarström A (2016) Associations between social support and depressive symptoms: social causation or social selection-or both? Eur J Public Health ckw120. doi:10.1093/eurpub/ckw120

5. Giacco D, Amering M, Bird V, Craig T, Ducci G, Gallinat J, Jovanovic N (2016) Scenarios for the future of mental health care: a social perspective. Lancet Psychiatry. http://www.sciencedirect.com/science/article/pii/S221503661630219X. Accessed January 2017

6. National Institute for Health and Care Excellence (NICE) (2016) Depression in adults: recognition and management. Clinical Guideline [CG90]. https://www.nice.org.uk/guidance/cg90. Accessed January 2017

7. National Institute for Health and Care Excellence (NICE) (2016) Psychosis and schizophrenia in adults: Clinical Guideline
[CG178]. https://www.nice.org.uk/guidance/cg178. Accessed January 2017

8. The Guardian (2017) Happiness study lets psychologists off the hook. https://www.theguardian.com/society/2016/dec/26/ happiness-lse-study-austerity-off-the-hook-psychologists-claim. Accessed January 2017

9. Priebe S, Burns T, Craig, TKJ (2013) The future of academic psychiatry may be social. Br J Psychiatry 201:319-320

10. Mental Health Taskforce to the NHS in England (2015) The Five Year Forward View Mental Health Taskforce: Public Engagement Findings. https://www.england.nhs.uk/mentalhealth/wpcontent/uploads/sites/29/2015/09/fyfv-mental-hlth-taskforce.pdf. Accessed January 2017

11. Wykes T, Haro JM, Belli SR, Obradors-Tarragó C, Arango C, Ayuso-Mateos JL, Elfeddali I (2015) Mental health research priorities for Europe. Lancet Psychiatry 2(11):1036-1042

12. Marshall T, Goldberg RW, Braude L, Dougherty RH, Daniels AS, Ghose SS, Delphin-Rittmon ME (2014) Supported employment: assessing the evidence. Psychiatr Serv 65(1):16

13. Centre for Reviews and Dissemination (2015) Evidence to inform the commissioning of social prescribing. http://www. york.ac.uk/media/crd/Ev\%20briefing_social_prescribing.pdf. Accessed January 2017

14. McGorry P (2013) Prevention, innovation and implementation science in mental health: the next wave of reform. Br J Psychiatry, 202(s54): s3-s4

15. Annual Report of the Chief Medical Officer (2013) Public Mental Health: Investing in the Evidence. https://www.gov.uk/government/uploads/system/uploads/attachment_data/file/413196/ CMO_web_doc.pdf. Accessed January 2017

16. Cacioppo JT, Cacioppo S (2014) Social relationships and health: the toxic effects of perceived social isolation. Soc Personal Psychol Compass 8(2):58-72

17. Mann F, Bone J, Ma R, Pinfold V, Frerichs J, Lloyd-Evans B, Johnson S (forthcoming) Loneliness and mental health: a state of the art review. Soc Psychiatry Psychiatr Epidemiol

18. Webber MP, Fendt-Newlin M (2016) Social participation interventions for people with mental health problems: a state of the art review. Soc Psychiatry Psychiatr Epidemiol (in press)

19. Henderson C, Gronholm PC, Deb T, Thornicroft G (2016) Interventions to reduce discrimination and stigma: the state of the art. Soc Psychiatry Psychiatr Epidemiol (In press)

20. Wahlbeck K, Cresswell-Smith J. Haaramo P, Parkkonen J (2016) Interventions to mitigate the effects of poverty and inequality on mental health. (In press)

21. Modini M, Tan L, Brinchmann B, Wang MJ, Killackey E, Glozier N, Harvey SB (2016) Supported employment for people with severe mental illness: systematic review and meta-analysis of the international evidence. Br J Psychiatry 209(1):14-22

22. Woodhall-Melnik JR, Dunn JR (2016) A systematic review of outcomes associated with participation in Housing First programs. Hous Stud 31(3):287-304

23. Killaspy H (2016) Supported accommodation for people with mental health problems. World Psychiatry 15(1):74-75

24. Marmot J (2015) The health gap: the challenge of an unequal World. Bloomsbury, London

25. Pickett K, Wilkinson R (2010) The spirit level: why equality is better for everyone. Penguin Books Ltd, London

26. Smith KE, Eltanani MK (2015) What kinds of policies to reduce health inequalities in the UK do researchers support? J Public Health 37(1):6-17 